\title{
Prevalence of abnormal urinary cadmium and risk of albuminuria as a primary bioindicator for kidney problems among a healthy population
}

\author{
Mohd Faizal Madrim ${ }^{1,2}$, Mohd Hasni Jaafar ${ }^{\text {Corresp., } 1}$, Rozita Hod ${ }^{1}$ \\ ${ }^{1}$ Department of Community Health, Faculty of Medicine, Universiti Kebangsaan Malaysia, Kuala Lumpur, Federal Territory of Kuala Lumpur, Malaysia \\ 2 Department of Community and Family Medicine, Faculty of Medicine and Health Sciences, Universiti Malaysia Sabah, Kota Kinabalu, Sabah, Malaysia \\ Corresponding Author: Mohd Hasni Jaafar \\ Email address: drmhasni@ukm.edu.my
}

Background. The prevalence of chronic kidney disease is increasing globally, ranking 27th as the cause of death in the 1990s, rising to 18th in 2010 and 10th in 2019. Non-communicable diseases such as diabetes and hypertension have been identified as the common contributing factors, while there is also evidence linking environmental pollutants, especially cadmium, to kidney disease. This study aimed at investigating the level of urinary cadmium and its relationship to albuminuria as an early indicator of kidney problems in the Kepong community.

Methods. Respondents were surveyed as part of several health-related programs organized by the Kepong District Health Office involving local communities in and around the district from April 2019 to December 2019. Urinalysis of two urine samples was carried out using a Mission reagent strip and an Inductively Coupled Plasma Mass Spectrometry (ICP-MS) test to detect the presence and level of urinary cadmium.

Results. A total of 240 respondents were enrolled from April 2019 to December 2019. Urinalysis of two urine samples was carried out using a Mission reagent strip and an Inductively Coupled Plasma Mass Spectrometry (ICP-MS) test to detect the level of urinary cadmium. The respondents' average age was 41-year-old ( \pm 13.23). Among them, 49.6\% were male, $85.0 \%$ Malay, 5.8\% Chinese and $8.3 \%$ Indian. $55.0 \%$ had background of tertiary, $39.6 \%$ secondary and $5.4 \%$ primary level of education. $52.1 \%$ were categorized in B40, 34.6\% in M40 and $13.3 \%$ in T20 based on monthly household income category. $26.7 \%$ were hypertensive, $6.7 \%$ diabetic, $4.2 \%$ had dyslipidemia, $51.7 \%$ had urinary cadmium above the alert level, and $27.1 \%$ had albuminuria.

Discussion. Risk factors for albuminuria that have been identified are age with adjusted odds ratio (AOR) 3.53 (1.41-8.83; $p<0.05)$, highest educational level with AOR 2.18 (1.14-4.17; $p<0.05)$, diabetes with AOR 3.36 (1.07-10.52; $p<0.05)$, and urinary cadmium with AOR $4.72(2.33-9.59 ; p<0.001)$, with future screening programs placing greater attention to those at risk and further research is required to determine the cause of exposure to cadmium. 


\section{Prevalence of abnormal urinary cadmium and risk of} among a healthy population.

Mohd Faizal Madrim ${ }^{1,2}$, Mohd Hasni Jaafar ${ }^{1}$, Rozita Hod ${ }^{1}$

${ }^{1}$ Department of Community Health, Faculty of Medicine, Universiti Kebangsaan Malaysia, 9 Kuala Lumpur, Malaysia

$10{ }^{2}$ Department of Community and Family Medicine, Faculty of Medicine and Health Sciences, 11 Universiti Malaysia Sabah, Kota Kinabalu, Sabah, Malaysia

Corresponding Author:

14 Mohd Hasni Jaafar ${ }^{1}$

Jalan Yaacob Latif, Bandar Tun Razak, 56000 Kuala Lumpur, Wilayah Persekutuan Kuala Lumpur, Malaysia Email address: drmhasni1965@gmail.com / drmhasni@ukm.edu.my

\section{Abstract}

Background. The prevalence of chronic kidney disease is increasing globally, ranking 27 th as the cause of death in the 1990s, rising to 18th in 2010 and 10th in 2019. Non-communicable diseases such as diabetes and hypertension have been identified as the common contributing factors, while there is also evidence linking environmental pollutants, especially cadmium, to kidney disease. This study aimed at investigating the level of urinary cadmium and its relationship to albuminuria as an early indicator of kidney problems in the Kepong community.

Methods. Respondents were surveyed as part of several health-related programs organized by the Kepong District Health Office involving local communities in and around the district from April 2019 to December 2019. Urinalysis of two urine samples was carried out using a Mission reagent strip and an Inductively Coupled Plasma Mass Spectrometry (ICP-MS) test to detect the presence and level of urinary cadmium.

Results. A total of 240 respondents were enrolled from April 2019 to December 2019. Urinalysis of two urine samples was carried out using a Mission reagent strip and an Inductively Coupled Plasma Mass Spectrometry (ICP-MS) test to detect the level of urinary cadmium. The respondents' average age was 41-year-old ( \pm 13.23$)$. Among them, $49.6 \%$ were male, $85.0 \%$ Malay, 5.8\% 
Chinese and $8.3 \%$ Indian. $55.0 \%$ had background of tertiary, $39.6 \%$ secondary and $5.4 \%$ primary level of education. $52.1 \%$ were categorized in B40, 34.6\% in M40 and $13.3 \%$ in T20 based on monthly household income category (1). 26.7\% were hypertensive, $6.7 \%$ diabetic, $4.2 \%$ had dyslipidemia, 51.7\% had urinary cadmium above the alert level, and 27.1\% had albuminuria.

Discussion. Risk factors for albuminuria that have been identified are age with adjusted odds ratio (AOR) 3.53 (1.41-8.83; p<0.05), highest educational level with AOR 2.18 (1.14-4.17; p<0.05), diabetes with AOR 3.36 (1.07-10.52; $\mathrm{p}<0.05)$, and urinary cadmium with AOR 4.72 (2.33-9.59; $\mathrm{p}<0.001$ ), with future screening programs placing greater attention to those at risk and further research is required to determine the cause of exposure to cadmium.

\section{Introduction}

Chronic kidney disease (CKD) is a major non-communicable disease that contributes significantly to morbidity and mortality globally. One of the aims outlined in the UN's Sustainable Development Goal (SDG) is to decrease premature deaths from non-communicable diseases by one-third by 2030 and in order to achieve it, greater attention has to be given to this disease.

The number of people seeking treatment for this disease is increasing, with more than 2.5 million current reported. According to projections, the number could reach 5.4 million in a decade (2). Malaysia is experiencing a similar magnitude of the problem, where there was an 11-fold increase in the number of patients receiving hemodialysis treatment registered in the 22nd Malaysian Dialysis and Transplant Registry over a 10-year period (2004-2014) (3).

In general, there are two groups of risk factors contributing to the development of this disease: traditional and non-traditional. The traditional group mainly consists of metabolic disorders such as hypertension, diabetes mellitus, and obesity, while the non-traditional group consists of infections and drug-related disorders. There have been previous reports of CKD cases that were not related to either traditional or non-traditional risk factors $(4,5)$ but instead linked to environmental toxicants, specifically cadmium (Cd). $\mathrm{Cd}$ has specific properties that enable it to accumulate in kidneys and disrupt the system. Following exposure, $\mathrm{Cd}$ create a complex with metallothionein which initially filtered by glomerulus and subsequently reabsorbed at proximal and distal tubules. Upon entering tubular cells, lysosome breaks the complex to free $\mathrm{Cd}$ and initiates damage to kidneys. The process here includes oxidative stress, inflammatory cell infiltration and downregulating mitochondrial coenzymes (6-9). 
$66 \mathrm{CKD}$ is unlikely to exhibit obvious features or symptoms, especially in the early stages, increasing

67 the likelihood for it to be overlooked and albuminuria is one of the most basic tests for detecting

68

69 early signs of CKD (10). As there is still a lack of local awareness about the issue, this study aimed to determine the prevalence of high urinary $\mathrm{Cd}$ levels and assess their relationship with albuminuria as an early indicator of kidney disease in the Kepong, Klang Valley population.

\section{Materials \& Methods}

The general population of Kepong, Kuala Lumpur was selected for this cross-sectional study, and samples were collected from Kepong residents aged 18 years and above of both genders residing in Kepong, with informed consent obtained from every participant using a consent form for this study. The inclusion criteria were: (a) Malaysian nationality or permanent resident; (b) residing in Kepong for at least 10 years; and (c) consented for this study, whereby the exclusion critera were: (a) respondents with leucocytes $\geq 1+$ or positive nitrite detected in the dipstick urinalysis; (b) respondents whose urine sample showed red blood cells $\geq 1+$; respondents who had known kidney disease; and (c) respondents who failed to converse or understand Malay or English language. Every participant completed a self-administered questionnaire that included demographic, socioeconomic, smoking status, exercise, and also medical history. The participants' blood pressure (BP), heart rate, body mass index (BMI), blood glucose, and dipstick urinalysis were all measured on-site.

Weight was measured using the 'SECA 813 Digital High-Capacity Floor Scale, Japan', height was measured using the 'SECA 217 Stadiometer, Japan', blood pressure was measured using the 'Omron Digital Automatic Blood Pressure Monitor Model HEM-907, Omron Healthcare Co Ltd, Kyoto, Japan', and capillary blood glucose was measured using the Accu-Chek Performa 2 Glucometer.

Two separate disposable polypropylene containers were used to collect clean-catch, mid-stream urine specimens. The first container was for dipstick urinalysis (Mission Urinalysis Reagent Strips,) at the study site, while the second one was for a $\mathrm{Cd}$ check using Inductively Coupled Plasma Mass Spectrometry (ICP-MS) at the environmental laboratory in Universiti Kebangsaan Malaysia.

\section{$\underline{\text { Definitions }}$}


96 Urinary albumin-to-creatinine ratio (ACR, milligram per gram $(\mathrm{mg} / \mathrm{g})$ ) readings as the output of 97 the dipstick urinalysis were used to define albuminuria. According to the guideline of the American 98 Diabetes Association, microalbuminuria and macroalbuminuria were defined as increases in ACR 99 between 30 and $299 \mathrm{mg} / \mathrm{g}$ and $300 \mathrm{mg} / \mathrm{g}$ or higher, respectively, and referred to as 'albuminuria' 100 in this study.

101 High urinary Cd levels were determined using the Agency for Toxic Substances and Disease 102 Registry (ATSDR) and European Food Safety Authority (EFSA) reference values $(11,12)$, with 103 readings greater than $0.959 \mu \mathrm{g} / \mathrm{L}$ considered high levels of urinary $\mathrm{Cd}$.

104 Systolic BP $\geq 140 \mathrm{mmHg}$ or diastolic BP $\geq 90 \mathrm{mmHg}$ or self-reported diagnosis of high BP were 105 used to define hypertension. Those who had a history of diabetes mellitus or a fasting capillary 106 blood glucose $\geq 7.0 \mathrm{mmol} / \mathrm{L}$ or non-fasting capillary blood glucose $\geq 11.1 \mathrm{mmol} / \mathrm{L}$ (13) were 107 described as having diabetes mellitus. Participants were deemed to have fasted if they had not 108 eaten anything for at least 8 hours before the blood test. Self-reported diagnosis of deranged blood 109 cholesterol level was defined as dyslipidemia and a body mass index (BMI) of $\geq 30 \mathrm{~kg} / \mathrm{m}$ (14) was 110 defined as obesity.

\section{Statistical Analysis}

112 Analysis was carried out on data obtained from adults aged 18 years and older participating in the 113 screening program from April 2019 to October 2019, with those having incomplete data excluded. 114 Analysis was performed using Statistical Package for Social Sciences (SPSS) version 25. The

115 normally distributed continuous variables were summarized using the mean and standard deviation 116 (SD), while the non-normally distributed variables were expressed using the median and 117 interquartile range (IQR). For categorical variables, the frequencies and percentages (\%) were 118 tabulated. Univariate logistic regression was used to determine the unadjusted odds ratio (OR) for 119 albuminuria and the simultaneous effects of various risk factors, when adjusted for other 120 confounders, were determined using multivariable logistic regression.

121

122 This National University of Malaysia (UKM) granted Ethical approval to carry out the study. 123 (Ethical Approval Ref: UKM FPR.4/244/FF-2019-100, 22nd March 2019).

124

\section{Results}


126 A total of 240 people participated in this study. Table 1 displays the sample population's

127 characteristics and the participants were comprised of 50.4\% females, $85.0 \%$ ethnic Malays, 5.8\%

128 Chinese, $8.3 \%$ Indians, and $0.8 \%$ others, with an average age of 41.4 years. Among them, $45.0 \%$

129 did not have a high education level background and $52.1 \%$ were in the B40 group (bottom 40\%

130 of households with monthly income of RM3,152 and below according to Department of Statistics

131 Malaysia 2019). Hypertension was present in $14.6 \%$ of the participants, diabetes in $6.7 \%$ of the

132 participants, dyslipidemia in $4.2 \%$ of the participants, and obesity in $44.2 \%$ of the participants,

133 with no fasting respondents when their blood was taken for sugar check.

134 The ICP-MS 240 was used to screen Cd concentrations of urine samples and the detection limit

135 for Graphite Furnace Atomic Absorption Spectrometry (GFAAS) was as low as $0.1 \mu \mathrm{g} / \mathrm{L}$ urine

136 and the sensitivity of this analysis is $99 \%$.. High urinary $\mathrm{Cd}$ levels were present in $51.7 \%$ of the

137 participants and albuminuria was detected in $27.1 \%$ of the participants.

138 Bivariate Analysis

139 Table 2 shows that the geometric mean of urinary $\mathrm{Cd}$ is higher in females, Indians, and unemployed 140 people as compared to others. However, only the gender was found out to be statistically 141 significant, with a p-value of 0.008.

142 As shown in Table 3, a Pearson correlation test was performed and there was a moderate positive 143 correlation $(\mathrm{r}=0.386)$ between age and urinary Cd level, but a weak positive correlation $(\mathrm{r}=0.154)$ 144 between duration of stay in Kepong and urinary Cd level.

145 According to Table 4, there were no significant associations between albuminuria and gender, 146 ethnicity, working status, smoking status, obese and dyslipidemia. The proportion of those aged 14760 years and above, with a low education background, a low household income, were hypertensive, 148 diabetic, and had high urinary Cd with albuminuria was higher as compared to others.

149 Multivariate Analysis

150 Table 5 shows the adjusted odds ratio for albuminuria, with the adjusted analysis retaining all the 151 variables. Individuals with high urinary $\mathrm{Cd}$ levels displayed the highest risk for proteinuria, 152 followed by those aged 60 years old and above, who had diabetes, and without a high education 153 background.

154

155 Discussion

156 Based on the guidelines provided by ATSDR and EFSA, 51.7\% of the recruited samples for this 
157 study had high urinary Cd levels, which was different from the findings of previous studies that 158 have also been conducted in Malaysia. Adnan et al. (2012) reported a 14.7\% prevalence of high 159 urinary Cd levels among adults residing in Tanjung Karang, Selangor, and that the variations in 160 prevalence were influenced by reference source differences. The ATSDR and EFSA guidelines, 161 which focused more on kidney damage, were used in this study, while Adnan et al. (2012) used 162 the Michigan Occupational Safety and Health Administration (MIOSHA) as a reference, with 2 $163 \mu \mathrm{g} / \mathrm{L}$ as the action threshold level, which was approximately twice the reference level used in this 164 study. In addition, this difference was also most likely influenced by the study area as Kepong may have more Cd pollution sources compared to Tanjung Karang, causing the prevalence of Cd urine readings to be higher in Klang Valley. The prevalence of albuminuria for this study was $27.1 \%$, which fell within the range of previous studies' prevalence of albuminuria of $19.5 \%$ - 33.2\% (16-22). There are two main factors contributing to the different findings on the prevalence of albuminuria between this study and previous studies. First, is the selection of study respondents based on different acceptance and rejection criteria. For example, according to F. Chen et al. (2014), one of the rejection criteria of a respondent is someone who has been diagnosed with diabetes by a doctor and people with a history of diabetes were more likely to have albuminuria than others. This explains, to some extent, why the prevalence of albuminuria in this study was slightly greater compared to the finding of F. Chen et al. (2014). The second factor is the differences between the results on the prevalence of albuminuria were due to the albuminuria test itself. Previous studies have stated that several factors must be considered when testing for albuminuria, including the type of urine sample obtained, whether it is the initial flow, intermediate flow, or final flow, the unit of measurement used, whether it is uniform with any major references or not, and whether the albuminuria test should be repeated $(23,24)$. Besides the two factors mentioned above, researchers have also identified other factors that may influence prevalence differences for albuminuria, such as racial or ethnic differences (25) and diurnal fluctuations in albumin excretion (26).

183 It was discovered in this study, after controlling for confounding with Multiple Logistic Regression 184 analysis, that age, highest level of education, diabetes, and high urinary Cd levels were significant 185 predictive factors of albuminuria with a p-value of less than 0.05. Although the toxic effects of 186 heavy metals, including $\mathrm{Cd}$, on renal function, have been well documented (9,27-29), there is still 187 a lack of information on the associations between $\mathrm{Cd}$ and albuminuria in the general Malaysian 
188 population. It is important to understand that age has substantial influence on nephrotoxicity (30).

189 In previous cross-sectional studies, the commonly used "biomarkers" associated with renal disease 190 were a reduced estimated glomerular filtration rate (eGFR $<60 \mathrm{~mL} / \mathrm{min} / 1.73 \mathrm{~m} 2)$ and albuminuria

191 (urinary ACR $\geq 30 \mathrm{mg} / \mathrm{g}$ ) (31-34), although some authors referred to CKD as eGFR or urinary 192 ACR (35). This study reveals a significant risk for diabetes and albuminuria (adjusted odds ratio 193 (aOR) 3.36, 95\% CI 1.07, 10.52). This is consistent with the findings from previous study 194 involving Asian respondents $(18,36)$. It is well known that the pathogenesis of diabetic 195 nephropathy is related with renal fibrosis that can be caused by several factors namely renal 196 haemodynamic changes, glucose metabolism abnormalities-associated oxidative stress, 197 inflammatory processes and overactive renin-angiotensin-aldosterone system (37). In addition, 198 based on recent molecular studies, the pathogenesis is associated with genetic and epigenetic 199 regulation, mitochondria dysfunction and podocyte autophagy (38).

200 The relationship between urinary $\mathrm{Cd}$ and decreased GFR or albuminuria in adult participants of 201 the United States NHANES 2007-2012 was investigated by Buser et al. (2016) using multivariate 202 analysis and it was discovered that there was an important positive correlation between 203 albuminuria and urinary Cd (33). Furthermore, Grau-Perez et al. (2017) examined the relationship 204 between urinary Cd levels and albuminuria in adult participants who were part of the Hortega 205 Study, including a general Spanish population, and discovered using a multivariate analysis that 206 increased urinary $\mathrm{Cd}$ levels were significantly correlated with albuminuria (34). Findings from 207 both cross-sectional studies $(33,34)$ were similar to the findings of this study, where there was a 208 significant correlation between urinary $\mathrm{Cd}$ levels and albuminuria.

209 The results may be affected by ethnic and cultural differences between studies, such as local diets, 210 as well as variations in study designs. The present study, which discovered that Malays had a 211 higher risk of developing renal disease compared to others, highlighted the impact of ethnic 212 background on the risk of developing renal disease. Cd may be a contaminant in drinking water 213 and crops have been shown to absorb $\mathrm{Cd}$ from polluted soil and water; hence, variations in regional 214 water and soil contamination can affect outcomes. Furthermore, it is imperative to consider 215 biomarkers other than albuminuria that may be better at determining the correlations between 216 heavy metal exposure and renal disease.

217 The variations in the potential effects of $\mathrm{Cd}$ on renal disease development identified by the studies 218 listed above and the current study could be due to differences in study designs, study populations, 
219 and sensitivity of analyses. These disparities can reflect heterogeneity in the measures and methods

220 that were used to detect renal disease (e.g., eGFR, albuminuria, or proteinuria), which may have

221 varying degrees of sensitivity for the detection of renal disease. A study comparing proteinuria to

222 albuminuria as CKD biomarkers found that there was a significant correlation between 24-hour

223 proteinuria for protein to creatinine in urine and albumin-to-creatinine ratio (ACR) and that both

224 protein-to-creatinine ratio (PCR) and ACR were suitable biomarkers for cardiovascular events,

225 renal dysfunction, or mortality (39). However, studies like this one that evaluate the correlations

226 between the biological levels of heavy metals and a single potential renal disease biomarker like

227 albuminuria can only conclude that there is an association between specific heavy metals with a

228 certain biomarker, not the influence of heavy metals on renal disease development.

229 There are several limitations to this study that should be taken into consideration during the 230 interpretation of results. This study's cross-sectional design precludes the capability to determine 231 causality and cross-sectional data alone cannot adequately evaluate the complex association 232 between low-level biological $\mathrm{Cd}$ exposure and renal disease. Animal and clinical studies, 233 particularly longitudinal studies, are required for further evaluation of the relationship between 234 heavy metals exposure and renal disease development. The cross-sectional analysis could not 235 confirm whether low-level exposure to $\mathrm{Cd}$ led to actual kidney damage in people with albuminuria.

236 Furthermore, besides renal disease, other conditions may be the cause of albuminuria, which 237 possibly confounded our findings. Zhang et al. (2015) (40) recently suggested that N-acetyl- $\beta$-D238 glucosaminidase, metallothionein, and alkaline phosphatase were sensitive biomarkers for 239 evaluating long-term $\mathrm{Cd}$ exposure. There is a possibility that besides albuminuria, other 240 biomarkers could prove to be more sensitive for the evaluation of low-level heavy metal exposure 241 effects on renal function.

242

243 Conclusions

244 In conclusion, it has been shown through the multivariate results of this study that there was a 245 significant association between urinary Cd levels and albuminuria in Kepong, Kuala Lumpur, 246 Malaysia. Further studies are required to determine the possible source and effect of low-dose 247 heavy metals exposure, as well as other environmental factors, on renal function.

248

249 Acknowledgements 
250 This study was supported by the National University of Malaysia (UKM). (UKM FPR.4/244/FF251 2019-100, 22 $2^{\text {nd }}$ March 2019).

252

253

\section{References}

254 1. Malaysia D of S. T20, M40 And B40 Income Classifications In Malaysia. 2020.

255 2. Liyanage T, Ninomiya T, Jha V, Neal B, Patrice HM, Okpechi I, et al. Worldwide access to 256

257 treatment for end-stage kidney disease: A systematic review. Lancet [Internet]. 2015;385(9981):1975-82. Available from: http://dx.doi.org/10.1016/S01406736(14)61601-9

3. Goh BL, Ong LM, Lim YN. 22 nd REPORT OF THE MALAYSIAN DIALYSIS \&

4. Abumwais JQ. Renal Data from the Arab World. Ren Fail. 2012;23(1):158-61.

5. Athuraliya NTC, Abeysekera TDJ, Amerasinghe PH, Kumarasiri R, Bandara P, 263 Karunaratne U, et al. Uncertain etiologies of proteinuric-chronic kidney disease in rural Sri Lanka. Kidney Int [Internet]. 2011;80(11):1212-21. Available from: http://linkinghub.elsevier.com/retrieve/pii/S0085253815549727

6. Rana MN, Tangpong J, Rahman MM. Toxicodynamics of Lead, Cadmium, Mercury and Arsenic- induced kidney toxicity and treatment strategy: A mini review. Vol. 5, Toxicology Reports. 2018.

7. Naji A, Ismail A, Kamrani E, Sohrabi T. Correlation of MT levels in livers and gills with heavy metals in wild tilapia (Oreochromis mossambicus) from the Klang River, Malaysia. Bull Environ Contam Toxicol. 2014;92(6):674-9.

273

8. Saif M, Rahman UR, Ali MU, Shoaib M, Amin MA. Cadmium Induced Nephrotoxicity: Advances and Perspectives. Trends Biosci 8(19),. 2015;8(19):5167-75.

9. Johri N, Jacquillet G, Unwin R. Heavy metal poisoning: The effects of cadmium on the kidney. BioMetals. 2010;23(5):783-92.

10. Levey AS, Becker C, Inker LA. Glomerular filtration rate and albuminuria for detection and staging of acute and chronic kidney disease in adults: A systematic review. JAMA - J Am Med Assoc. 2015;313(8):837-46.

11. Services USD of H and H, Registry PHSA for TS and D. ToxGuide for Cadmium [Internet]. 2012 [cited 2020 May 2]. Available from: https://www.atsdr.cdc.gov/toxguides/toxguide- 
$281 \quad 5 . p d f$

282 12. Panel E, Chain F. Statement on tolerable weekly intake for cadmium. EFSA J. 2011;9(2).

283 13. Diabetes DOF. Diagnosis and classification of diabetes mellitus. Diabetes Care. 284 2013;36(SUPPL.1):67-74.

285 14. Third Report of the National Cholesterol Education Program (NCEP) Expert Panel on 286 Detection, Evaluation, and Treatment of High Blood Cholesterol in Adults (Adult Treatment Panel III) final report. Circulation. 2002 Dec;106(25):3143-421.

15. Adnan JA, Azhar SS, Hasni JM, Ahmad JS. Urinary cadmium concentration and its risk 289 factors among adults in Tanjung Karang, Selangor. Am J Toxicol Sci. 2012;4(June 2014):80-8.

16. Anand S, Khanam MA, Saquib J, Saquib N, Ahmed T, Alam DS, et al. High prevalence of 292 chronic kidney disease in a community survey of urban Bangladeshis: A cross-sectional study. Global Health. 2014;10(1):1-7.

17. Chen F, Yang W, Weng J, Jia W, Ji L, Xiao J, et al. Albuminuria: Prevalence, associated 295 risk factors and relationship with cardiovascular disease. J Diabetes Investig. 2014;5(4):464-71.

18. Kweon SS, Shin MH, Choi JS, Nam HS, Lee YH, Park KS, et al. Prevalence of albuminuria and associated cardiovascular risk factors: A community cohort in Namwon City, Korea. Diabetes Res Clin Pract [Internet]. 2012;97(3):492-8. Available from: http://dx.doi.org/10.1016/j.diabres.2012.05.018

19. Okpere AN, Anochie IC, Eke FU. Prevalence of microalbuminuria among secondary school 302 children. Afr Health Sci. 2012;12(2):140-7.

20. Zacharias JM, Young TK, Riediger ND, Roulette J, Bruce SG. Prevalence, risk factors and awareness of albuminuria on a Canadian First Nation: a community-based screening study. BMC Public Health. 2012;12:290.

21. Zheng LY, Umans JG, Tellez-Plaza M, Yeh F, Francesconi KA, Goessler W, et al. Urine arsenic and prevalent albuminuria: Evidence from a population-based study. Am J Kidney

from: http://dx.doi.org/10.1053/j.ajkd.2012.09.011

22. Zhuo M, Jiang MY, Song R, Mothi SS, Bellou S, Polding LC, et al. High Prevalence and Low Awareness of Albuminuria in the Community Setting in the KDSAP. Kidney Int 
Reports [Internet]. 2020;5(4):475-84.

Available

from:

313

314

315

316

317

318

319

320

321

322

323

324

325

326

327

328

329

330

331

332

333

334

335

336

337

338

339

340

341

342 https://doi.org/10.1016/j.ekir.2019.12.011

23. Chiang SC, Lee JK, Chen CH, Chuang LM, Tsan KW, Sheu WHH, et al. Justifying the high prevalence of microalbuminuria for type 2 diabetic patients in Taiwan with conditional probability approach-a DEMAND II Study. J Chinese Med Assoc. 2011;74(1):3-10.

24. Lu B, Wen J, Song XY, Dong XH, Yang YH, Zhang ZY, et al. High prevalence of albuminuria in population-based patients diagnosed with type 2 diabetes in the Shanghai downtown. Diabetes Res Clin Pract. 2007;75(2):184-92.

25. Kenealy T, Elley CR, Collins JF, Moyes SA, Metcalf PA, Drury PL. Increased prevalence of albuminuria among non-European peoples with type 2 diabetes. Nephrol Dial Transplant. 2012;27(5):1840-6.

26. Miller WG, Bruns DE, Hortin GL, Sandberg S, Aakre KM, McQueen MJ, et al. Current issues in measurement and reporting of urinary albumin excretion. Clin Chem. 2009;55(1):24-38.

27. Soderland P, Lovekar S, Weiner DE, Brooks DR, Kaufman JS. Chronic Kidney Disease Associated With Environmental Toxins and Exposures. Vol. 17, Advances in Chronic Kidney Disease. 2010. p. 254-64.

28. Evans M, Elinder CG. Chronic renal failure from lead: Myth or evidence-based fact. Vol. 79, Kidney International. 2011.

29. Järup L. Hazards of heavy metal contamination. Vol. 68, British Medical Bulletin. 2003.

30. El-Arabey AA. Sex and age differences related to renal oct2 gene expression in cisplatininduced nephrotoxicity. Vol. 9, Iranian Journal of Kidney Diseases. 2015.

31. Chung S, Chung JH, Kim SJ, Koh ES, Yoon HE, Park CW, et al. Blood lead and cadmium levels and renal function in Korean adults. Clin Exp Nephrol. 2014;18(5):726-34.

32. Weaver V, Navas-Acien A, Tellez-Plaza M, Guallar E, Muntner P, Silbergeld E, et al. Blood cadmium and lead and chronic kidney disease in US sdults: A joint analysis. Am J Epidemiol. 2009;170(9):1156-64.

33. Buser MC, Ingber SZ, Raines N, Fowler DA, Scinicariello F. Urinary and blood cadmium and lead and kidney function: NHANES 2007-2012. Int J Hyg Environ Health [Internet]. 2016;219(3):261-7. Available from: http://dx.doi.org/10.1016/j.ijheh.2016.01.005

34. Grau-Perez M, Pichler G, Galan-Chilet I, Briongos-Figuero LS, Rentero-Garrido P, Lopez- 
343 Izquierdo $\mathrm{R}$, et al. Urine cadmium levels and albuminuria in a general population from 344 Spain: A gene-environment interaction analysis. Environ Int [Internet]. 2017;106(May):27-

345 36. Available from: http://dx.doi.org/10.1016/j.envint.2017.05.008

346 35. Kim NH, Hyun YY, Lee KB, Chang Y, Rhu S, Oh KH, et al. Environmental heavy metal exposure and chronic kidney disease in the general population. J Korean Med Sci. 2015;30(3).

349 36. Satirapoj B, Supasyndh O, Mayteedol N, Chaiprasert A, Choovichian P. Metabolic syndrome and its relation to chronic kidney disease in a Southeast Asian population. Southeast Asian J Trop Med Public Health. 2011;42(1).

352 37. Melmed S, Polonsky KS, Larsen PR, Kronenberg HM. Williams Textbook of Endocrinology E-Book. Elsevier Health Sciences; 2015.

354 38. Lin YC, Chang YH, Yang SY, Wu KD, Chu TS. Update of pathophysiology and management of diabetic kidney disease. Vol. 117, Journal of the Formosan Medical Association. 2018.

39. Guh JY. Proteinuria versus albuminuria in chronic kidney disease. Nephrology.

40. Zhang YR, Wang P, Liang XX, Tan CS, Tan J Bin, Wang J, et al. Associations between urinary excretion of cadmium and renal biomarkers in nonsmoking females: A crosssectional study in rural areas of South China. Int $\mathrm{J}$ Environ Res Public Health. 2015;12(10):11988-2001. 
Table $\mathbf{1}$ (on next page)

Sociodemographic and health profiles of participants 


\section{Table 1:}

2 Sociodemographic and health profiles of participants.

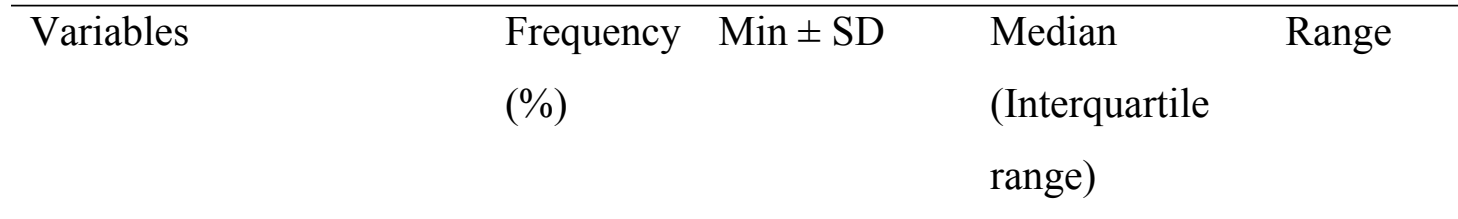

\section{Gender}

Male

$119(49.6)$

Female

$121(50.4)$

Age (years)

$41.41 \pm 13.23$

$18-74$

$<60$

213 (88.8)

$\geq 60$

$27(11.2)$

\section{Ethnicity}

Malay

$204(85.0)$

Chinese

$14(5.8)$

Indian

$20(8.3)$

Others

$$
2(0.8)
$$

\section{Education level}

Primary

13 (5.4)

Secondary

95 (39.6)

Tertiary

$132(55.0)$

\section{Working status}

Working

$156(65.0)$

Not working

$84(35.0)$

Monthly household

income category

$\begin{array}{ll}3000.00 & 600.00- \\ (1500.00) & 20000.00\end{array}$

B40

$125(52.1)$

M40

83 (34.6)

T20

32 (13.3)
Duration of staying in
$23.82 \pm 12.21$
$5-63$

\section{Kepong (years)}

\section{Smoking status}


Smoking

Not smoking

Known case of

hypertension

Yes

No

Known case of diabetes

Yes

No

Known case of

dyslipidemia

Yes

No

Body mass index

$(\mathrm{kg} / \mathrm{m} 2)$

Obese

Yes

No

Blood pressure (mmHg)

Systolic

Systolic $\geq 140 \mathrm{mmHg}$

(Ya)

Diastolic

Diastolic $\geq 90 \mathrm{mmHg}$

(Ya)

Blood sugar level

$(\mathbf{m m o l} / \mathrm{L})$
$10(4.2)$

$104(43.3)$

$136(56.7)$

$19(7.9)$

$221(92.1)$

$229(95.4)$

$230(95.8)$
34 (14.2)
$15.56-$

$106(44.2)$

134 (55.8)

$26.85 \pm 5.91$

\subsection{5}

$123.82 \pm$

$86-168$

14.55

35 (14.6)

$79.10 \pm 9.44$

$54-110$

$6.0(5.3)$

$3.9-21.1$

3 
Table 2 (on next page)

Urinary cadmium level of participants. 


\section{Table 1:}

2 Urinary cadmium level of participants.

\begin{tabular}{llll}
\hline Variables & Frequency & Geometric mean $(\boldsymbol{\mu g} / \mathbf{L})(\mathbf{S D})$ & Statistical Tests \\
\hline Gender & 119 & $0.809(1.910)$ & $\mathrm{t}=2.654$ \\
Male & 121 & $1.062(2.399)$ & $\mathrm{p}=0.008$ \\
Female & & $0.914(2.188)$ & \\
Ethnicity & & $0.946(1.535)$ & $\mathrm{F}=0.490$ \\
Malay & 204 & $1.097(3.155)$ & $\mathrm{p}=0.689$ \\
Chines & 14 & $0.615(1.035)$ & \\
Indian & 20 & & $\mathrm{t}=0.472$ \\
Others & 2 & & $\mathrm{p}=0.637$ \\
Working & & $0.911(2.170)$ & \\
status & & $0.959(2.334)$ & \\
Working & 156 & & \\
Not & 84 & & \\
working & & & \\
\hline
\end{tabular}

3

4 
Table 3 (on next page)

Correlation between urinary cadmium and continuous variables. 


\section{Table 1:}

2 Correlation between urinary cadmium and continuous variables.

\begin{tabular}{lll}
\hline & \multicolumn{2}{l}{ Urine cadmium level $(\mu \mathrm{g} / \mathrm{L})$} \\
\cline { 2 - 3 } Variables & $\begin{array}{l}\text { Correlation } \\
\text { coefficient, } \mathrm{r}\end{array}$ & Nilai $\mathrm{p}$ \\
& & \\
\hline Age (years) & $0.386^{* *}$ & $<0.001$ \\
Duration of staying in Kepong & $0.154^{*}$ & 0.017 \\
(years) & & \\
\hline
\end{tabular}

$* *$ p-value of $<0.01$ is considered significant

$*$ p-value of $<0.05$ is considered significant

3 
Table 4 (on next page)

Simple logistic regression. 


\section{Table 1:}

2 Simple logistic regression.

\begin{tabular}{llllll}
\hline Variables & Frequen & Albuminuria & & X2 (df) & P-value \\
\cline { 3 - 4 } & cy & Yes & No & & \\
\hline Gender & 119 & $31(26.1 \%)$ & $88(73.9 \%)$ & $0.13(1)$ & 0.721 \\
Male & 121 & $34(28.1 \%)$ & $87(71.9 \%)$ & & \\
Female & & & & & \\
Ethnicity & 204 & $55(27.0 \%)$ & $149(73.0 \%)$ & & \\
Malay & 14 & $2(14.3 \%)$ & $12(85.7 \%)$ & $3.60(3)$ & $0.345 \mathrm{a}$ \\
Chinese & 20 & $8(40.0 \%)$ & $12(60.0 \%)$ & & \\
Indian & 2 & $0(0.0 \%)$ & $2(100.0 \%)$ & & \\
Others & & & & & \\
Age (years) & 213 & $49(23.0 \%)$ & $164(77.0 \%)$ & $15.95(1)$ & $<0.001$ \\
$<60$ & 27 & $16(59.3 \%)$ & $11(40.7 \%)$ & & \\
$\geq 60$ & & & & &
\end{tabular}

High

education

background?

$\begin{array}{llllll}\text { Yes } & 132 & 23(17.4 \%) & 109(82.6 \%) & 13.86(1) & <0.001 \\ \text { No } & 108 & 42(38.9 \%) & 66(61.1 \%) & \end{array}$

Working

status

$\begin{array}{lccccc}\text { Not working } & 84 & 28(33.3 \%) & 56(66.7 \%) & 2.56(1) & 0.110 \\ \text { Working } & 156 & 37(23.7 \%) & 119(76.3 \%) & & \\ \text { Monthly } & & & & & \\ \text { household } & & & & & \\ \text { income }- \text { B40? } & & & & & \\ \text { No } & 115 & 19(16.5 \%) & 96(83.5 \%) & 12.47(1) & <0.001 \\ \text { Yes } & 125 & 46(36.8 \%) & 79(63.2 \%) & & \end{array}$

Smoking

status 


$\begin{array}{llllll}\text { Not smoking } & 136 & 36(26.5 \%) & 100(73.5 \%) & 0.06(1) & 0.807 \\ \text { Smoking } & 104 & 29(27.9 \%) & 75(72.1 \%) & & \\ \text { Obese } & & & & & \\ \text { No } & 134 & 31(23.1 \%) & 103(76.9 \%) & 2.40(1) & 0.122 \\ \text { Yes } & 106 & 34(32.1 \%) & 72(67.9 \%) & & \end{array}$

\section{Hypertensive}

$\begin{array}{llllll}\text { No } & 176 & 38(21.6 \%) & 138(78.4 \%) & & \\ \text { Yes } & 64 & 27(42.2 \%) & 37(57.8 \%) & & \end{array}$

\section{Diabetes}

$\begin{array}{llllll}\text { No } & 224 & 55(24.6 \%) & 169(75.4 \%) & & \\ \text { Yes } & 16 & 10(62.5 \%) & 6(37.5 \%) & & \end{array}$

\section{Dyslipidaemia}

$\begin{array}{llllll}\text { No } & 230 & 63(27.4 \%) & 167(72.6 \%) & & \\ \text { Yes } & 10 & 2(20.0 \%) & 8(80.0 \%) & & 1.000\end{array}$

\section{Urine}

cadmium level

\begin{tabular}{lllll} 
Low & 116 & $13(11.2 \%)$ & $103(88.8 \%)$ & $28.66(1)$ \\
High & 124 & $52(41.9 \%)$ & $72(58.1 \%)$ & \\
\hline
\end{tabular}

3

4 
Table 5 (on next page)

Multiple logistic regression. 
1 Table 1:

2 Multiple logistic regression.

\begin{tabular}{|c|c|c|c|c|}
\hline Variables & $\begin{array}{l}\text { Adjusted } \\
\text { odds ratio }\end{array}$ & $\begin{array}{l}95 \% \\
\text { Confidence } \\
\text { Interval }\end{array}$ & X2 (df) & P-value \\
\hline \multicolumn{5}{|c|}{ Age (years) } \\
\hline$<60$ & 1 & & & \\
\hline$\geq 60$ & 3.53 & $1.41 ; 8.83$ & $7.28(1)$ & 0.007 \\
\hline \multicolumn{5}{|c|}{ High education } \\
\hline Yes & 1 & & & \\
\hline No & 2.18 & $1.14 ; 4.17$ & $5.51(1)$ & 0.019 \\
\hline \multicolumn{5}{|l|}{ Diabetic } \\
\hline No & 1 & & & \\
\hline Yes & 3.36 & $1.07 ; 10.52$ & $4.33(1)$ & 0.038 \\
\hline \multicolumn{5}{|c|}{ Urine cadmium level } \\
\hline Low & 1 & & & \\
\hline High & 4.72 & $2.33 ; 9.59$ & $18.47(1)$ & $<0.001$ \\
\hline
\end{tabular}

3 